Article

\title{
Effects of the Hydrophilic-Lipophilic Balance of Alternating Peptides on Self-Assembly and Thermo-Responsive Behaviors
}

\author{
Abu Bin Ihsan (D), Mahmuda Nargis and Yasuhito Koyama *D \\ Department of Pharmaceutical Engineering, Faculty of Engineering, Toyama Prefectural University, \\ 5180 Kurokawa, Imizu, Toyama 939-0398, Japan; ihsan@pu-toyama.ac.jp (A.B.I.); nargis@pu-toyama.ac.jp (M.N.) \\ * Correspondence: ykoyama@pu-toyama.ac.jp; Tel.: +81-766-56-7500 (ext. 1791)
}

Received: 25 July 2019; Accepted: 11 September 2019; Published: 17 September 2019

\begin{abstract}
A series of $N$-substituted poly(Gly-alter-Val) peptides were successfully synthesized for the systematic evaluation of the micellization behavior of alternating peptides. Three-component polymerization employing an aldehyde, a primary ammonium chloride, and potassium isocyanoacetate afforded four alternating peptides in excellent yields. We investigated the dependence of the hydrophilic-lipophilic balance of alternating peptides on the micellization behavior. All the aqueous solutions of alternating peptides exhibited upper critical solution temperature (UCST) behaviors, strongly indicating that the alternating binary pattern would mainly contribute to the UCST behaviors. The cloud points of alternating peptides shifted to higher temperatures as the side chains became more hydrophilic, which is opposite to the trend of typical surfactants. Such unusual micellization behaviors appeared to be dependent on the quasi-stable structure of single polymer chains formed in water.
\end{abstract}

Keywords: alternating peptide; amphiphilic peptide; multi-component polycondensation; cloud point; critical micelle concentration

\section{Introduction}

Amphiphilic peptides form associates in water, such as micelles and vesicles, as a result of the self-assembly of single polymer chains [1]. Peptide-based associates have a potential use as drug carriers that enable the encapsulation or controlled release of drugs. For the innovation of pharmacological therapies, extensive efforts have been devoted to the creation of peptide-based drug carriers using amphiphilic peptides with the rational permutation of hydrophobic and hydrophilic amino acids [2-5]. However, the synthesis of amphiphilic peptides is based on labor-intensive, stepwise condensation reactions of amino acids, which restricts industrial applications. The bottom-up examination of self-assembled peptides strongly requires a simple structural motif for the systematic investigation and tuning of properties because it includes comprehensive studies to evaluate the correlations between (i) the amino acid sequence, (iii) the quasi-stable native 3D structure, (iii) the thermally stable structure perturbed by external stimuli, and (iv) the properties of associates.

Recently, we reported the impact of the amino acid sequence on peptide structure in aqueous solution and investigated the thermo-responsive behaviors of diblock, random, and alternating copolypeptides consisting of stoichiometric amounts of L-valine (L-Val) as a hydrophobic unit and glycine (Gly) as a hydrophilic unit (Figure 1a) [6]. The aqueous polymer solutions exhibited different thermal responsivity depending on the polymer sequence. It was found that the UV spectra of a diblock copolymer at various temperatures exhibited a cloud point, indicating that the polymer adopted coil-to-globule transition upon heating. The alternating peptide showed an upper critical solution temperature (UCST), which was found to be independent of the chirality of repeating units but 
influenced by the alternating binary pattern of hydrophobic and hydrophilic units. On the other hand, a random copolypeptide exhibited not only coil-to-globule transition at low temperatures but also globule-to-coil transition at high temperature owing to the presence of both segregated and alternating polymer sequences in the polymer.

(a)

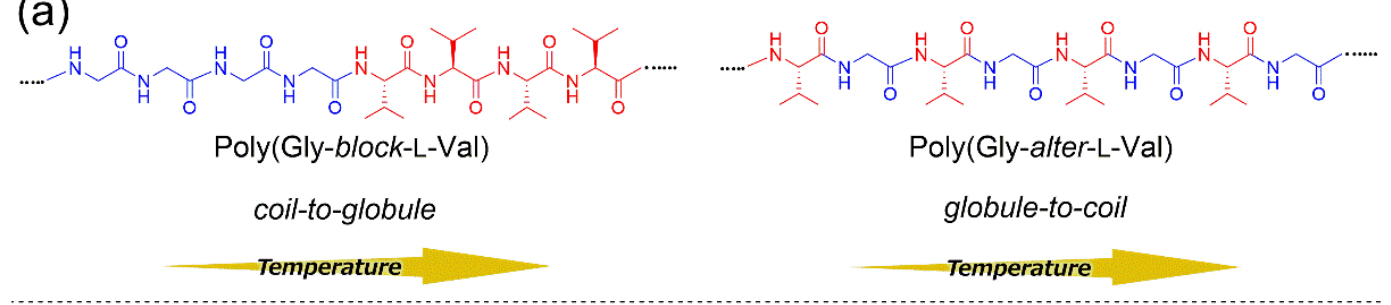

(b)

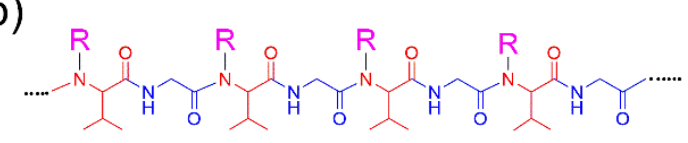

1) globule-to-coil transition upon heating

2) self-assembly in water

3) cloud point: $R=$ hydroxyethyl $\longrightarrow$ high $\mathrm{R}=n$-propyl $\longrightarrow$ low

Figure 1. (a) Thermo-responsiveness of poly(Gly-block-L-Val) as a diblock copolypeptide and poly(Gly-alter-L-Val) as an alternating peptide (previous work) and (b) self-assembly and thermo-responsive properties of alternating peptides (current work).

In this work, we studied the self-assembly and thermo-responsive properties of newly synthesized poly(Gly-alter-Val) derivatives (Figure 1b). For the exploitation of the micellar properties of alternating peptides, we designed and synthesized $N$-substituted poly(Gly-alter-Val) derivatives and investigated the dependence of the hydrophilic-lipophilic balance of alternating peptides on the micellization behavior. It turned out that all the aqueous solutions of alternating peptides exhibited UCST behaviors, strongly indicating that the alternating binary pattern would contribute to the UCST behaviors. By the introduction of $n$-propyl groups as a hydrophobic functionality to the side chains, the polymers showed a cloud point in high-temperature regions. It was found that the cloud points of alternating peptides shifted to a higher temperature as the side chains became more hydrophilic, which is clearly opposite to the trend of typical surfactants [7]. We discuss the unusual micellization behaviors of alternating peptides through the estimation of single polymer chain structures in water.

\section{Results and Discussion}

We first prepared an alternating peptide consisting of Gly and L-Val via the conventional polycondensation of glycyl-L-valine as a dipeptide monomer and O-(7-azabenzotriazole-1-yl)$N, N, N^{\prime}, N^{\prime}$-tetramethyluronium hexafluorophosphate (HATU) as a dehydrator (Scheme 1a). Treatment of the dipeptide with HATU in the presence of $\mathrm{Et}_{3} \mathrm{~N}$ in DMSO for $8 \mathrm{~d}$ at room temperature afforded poly(Gly-alter-L-Val) as a white solid. We next synthesized N-ethylated poly(Gly-alter-Val), Et-Pep according to our recently developed technique for the one-pot synthesis of alternating peptides, with a slight modification [8]. Since our reported procedure is based on the use of alkylammonium trifluoromethanesulfonate, the work-up absolutely requires water treatment to remove amphiphilic potassium trifluoromethanesulfonate from the products. Assuming that Et-Pep would be highly soluble in water, making the extraction of products difficult, we exploited ethylammonium hydrochloride in place of ethylammonium trifluoromethanesulfonate as the reaction component of the three-component polymerization. A mixture of three components, i.e., isobutyraldehyde, ethylammonium hydrochloride, and potassium isocyanoacetate in $i-\mathrm{PrOH}$ was stirred for $8 \mathrm{~d}$ at room temperature and concentrated in vacuo. The resulting crude mixture was further stirred for $6 \mathrm{~d}$ at room temperature and afforded a highly viscous material. Tetrahydrofuran (THF) was added to the crude mixture to precipitate $\mathrm{KCl}$, and the mixture was filtered and concentrated in vacuo to give N-ethylated poly (Gly-alter-Val), Et-Pep, as an amorphous compound, in the quantitative yield (Scheme 1b). The structure of Et-Pep was found to be an exactly alternating peptide structure, which was confirmed by the ${ }^{1} \mathrm{H} \mathrm{NMR},{ }^{13} \mathrm{C} N M R$, 
and IR spectra (Figures S4, S5 and S8) according to the literature [8]. The results suggest that the use of alkylammonium chloride makes the work-up process easy, without serious influence on the polymerization results.

(a)
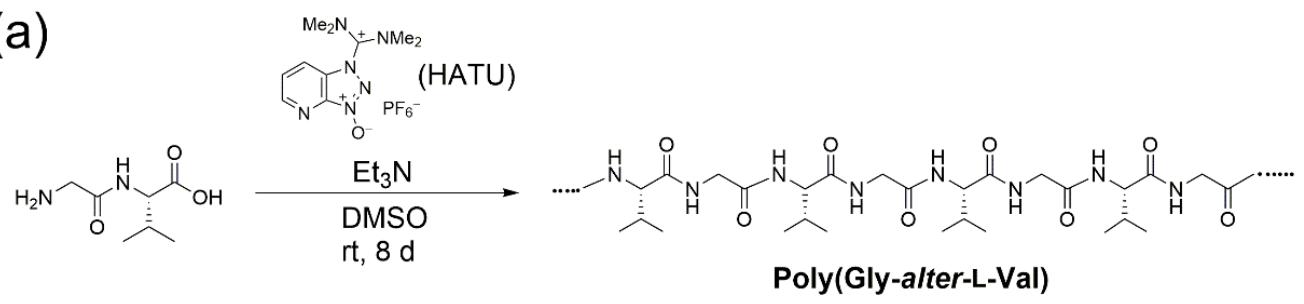

(b)<smiles>C[N+]#CCC(=O)OCCCN[Si]Cl</smiles><smiles>OCCCCCCC(Cl)(Cl)Cl</smiles><smiles>CCN(CC)C(C(=O)NC)C(C)C</smiles>

$\mathrm{KCl}, \mathrm{H}_{2} \mathrm{O}$

Poly(Gly-alter-L-Val)

Scheme 1. (a) Synthesis of poly(Gly-alter-L-Val) as alternating peptides via conventional polycondensation of a dipeptide monomer and (b) one-pot synthesis of Et-Pep via three-component polymerization.

We measured the UV-vis spectra of these polymers at various concentrations to know the critical micelle concentration (CMC) (Figures S24 and S25), i.e., the onset concentration to form micelles according to the literature [9-15]. The absorbance was plotted against the logarithm of polymer concentration (Figure 2a,b). Each figure clearly includes an intersection point as the CMC of the polymers in water, supporting the formation of micelles. The CMCs were found to be approximately $0.2 \mathrm{wt} \%$ for the two polymers, indicating that the $N$-ethyl substitutions on the poly(Gly-alter-Val) skeleton hardly affected the CMC value. We next measured the UV-vis spectra of the aqueous solutions at various temperatures [10] and plotted the dependence of transmittance at $450 \mathrm{~nm}$ on temperature (Figure 2 and Figure S26). The plots indicated that both solutions exhibited a UCST-like transition. In the plots, the onset temperature to become translucent upon cooling is defined as a cloud point. The cloud points of both alternating peptides appear at below room temperature. The results confirmed that the regularly arranged binary pattern of hydrophobic and hydrophilic units in the alternating peptide would contribute to such UCST behaviors. Interestingly, the cloud point of poly(Gly-alter-L-Val) appeared at a higher temperature than that of Et-Pep, despite Et-Pep having hydrophobic alkyl side chains.

(a)

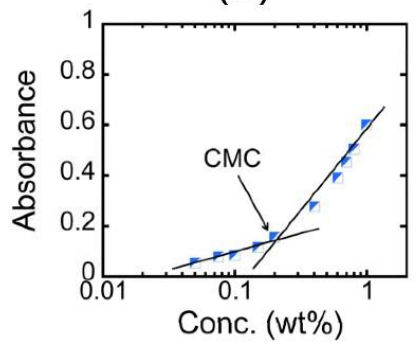

(b)

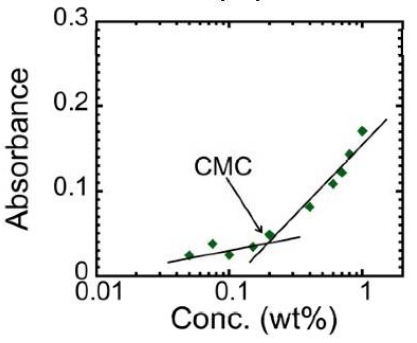

(c)

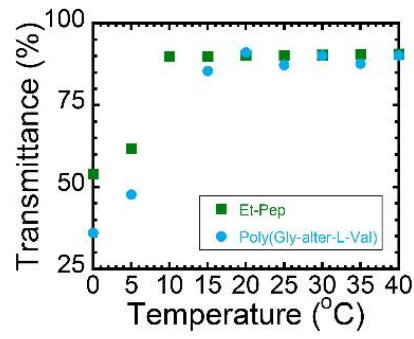

Figure 2. The absorbance of (a) poly(Gly-alter-L-Val) and (b) Et-Pep as a function of concentration (wt \%) at $25{ }^{\circ} \mathrm{C}$ and (c) the temperature-dependence of transmittance of poly(Gly-alter-L-Val) (blue circle) and Et-Pep (green square) at $450 \mathrm{~nm}(1.5 \mathrm{wt} \%)$.

To know the correlations between the structures and the cloud points described above, we compared the IR spectra of the polymers (Figures S3 and S8). The partial IR spectra in a range 
of $1700-1600 \mathrm{~cm}^{-1}$ are shown in Figure 3. In the IR spectrum of poly(Gly-alter-L-Val), the amide carbonyl signal appears at $1628 \mathrm{~cm}^{-1}$, which is in a good agreement with the amide wavelength originating from a $\beta$-sheet structure $[16,17]$, indicating the formation of a well-packed $\beta$-sheet structure in poly(Gly-alter-L-Val). On the other hand, the signal of Et-Pep is at $1647 \mathrm{~cm}^{-1}$, which is attributed to an $\alpha$-helix or a random-coil structure. Since the regulation of chiral stereo-centers on Et-Pep was not considered during the polymerization reaction, the IR absorption wavelength of the amide carbonyl group suggests that Et-Pep adopts a flexible random-coil structure. The ethyl substitutions on the amides of Et-Pep may disturb hydrogen bond formation in the $\beta$-sheet structure. In addition, the main chain structure of Et-Pep includes $N, N$-disubstituted amides. It has been reported that the $\mathrm{N}, \mathrm{N}$-disubstitution of amides remarkably decreases the trans-cis rotation energy [18,19]. Therefore, the low rotation energy of $\mathrm{N}, \mathrm{N}$-disubstituted amides might also facilitate the formation of the random-coil structure. The results imply that the rigid $\beta$-sheet formation in the polymer on the interface upon cooling could aid the association of peptide amphiphiles [20].

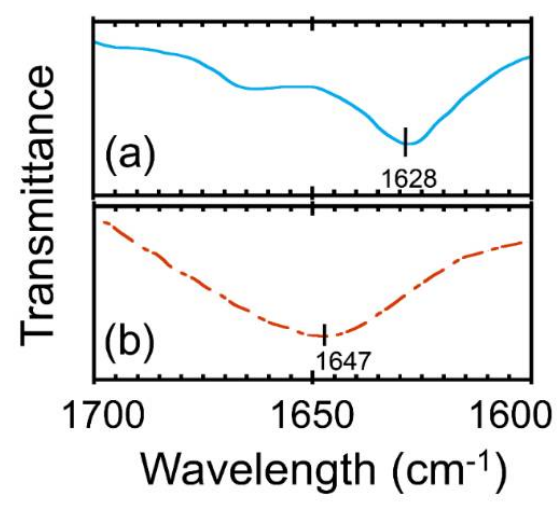

Figure 3. Partial IR spectra of (a) poly(Gly-alter-L-Val) and (b) Et-Pep (attenuated total reflection, ATR).

For the creation of alternating peptides with a lower cloud point than that of Et-Pep, we decided to synthesize HE-Pep, with hydroxyl groups in the side chains as a polar functionality (Scheme 2). We also prepared Pr-Pep and Me-Pep as control samples. According to the synthetic procedure shown in Scheme 1, the treatment of isobutyraldehyde, potassium isocyanide, and the corresponding alkylammonium hydrochlorides afforded HE-Pep, Pr-Pep, and Me-Pep as alternating peptides in quantitative yields (Figures S9, S14 and S19). In the IR spectra of three polymers (Figures S13, S18 and S23), the amide carbonyl signals appeared at around $1647 \mathrm{~cm}^{-1}$ without a shoulder at $1628 \mathrm{~cm}^{-1}$, indicating that the polymers adopted a random-coil structure as a native structure.

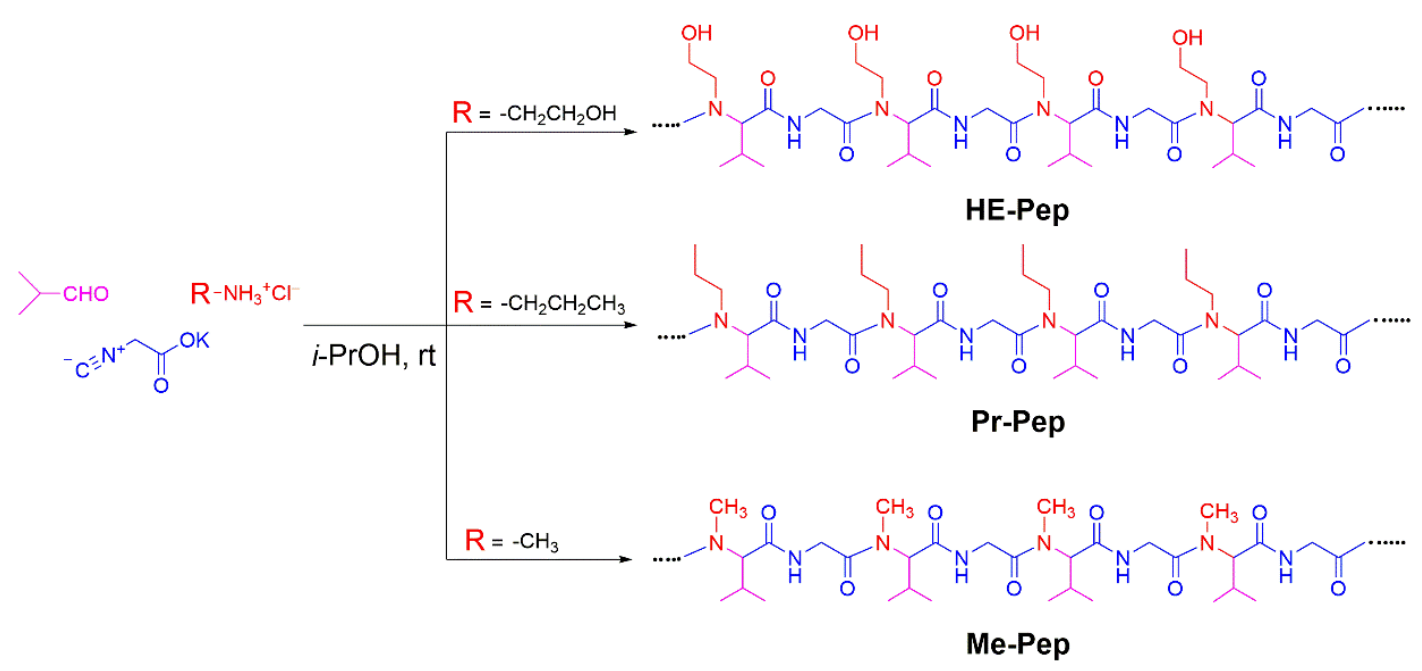

Scheme 2. Synthesis of alternating peptide-based amphiphiles with different side chains. 
With three polymers in hand, we estimated the CMC values by the UV-vis spectral measurements of the polymers in water (Figure 4). The absorbance was plotted against the logarithm of polymer concentration. Each figure clearly includes an intersection point as the CMC of the polymers in water, indicating the micellization of the polymers above the CMC. The CMCs were found to be approximately $0.2 \mathrm{wt} \%$ for all polymers, suggesting the independence of the structures of $\mathrm{N}$-substituents on the CMC value.

(a)

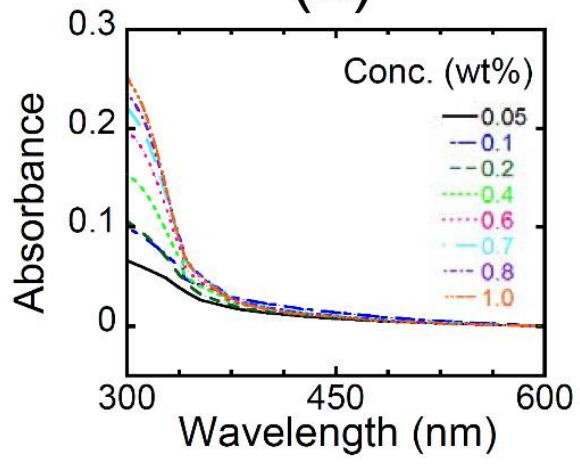

(b)

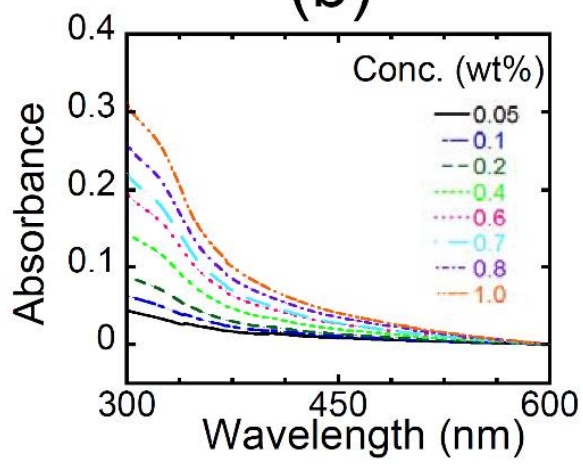

(c)

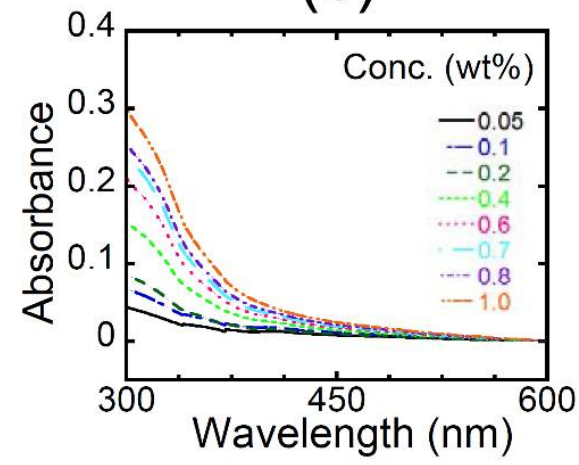

(d)

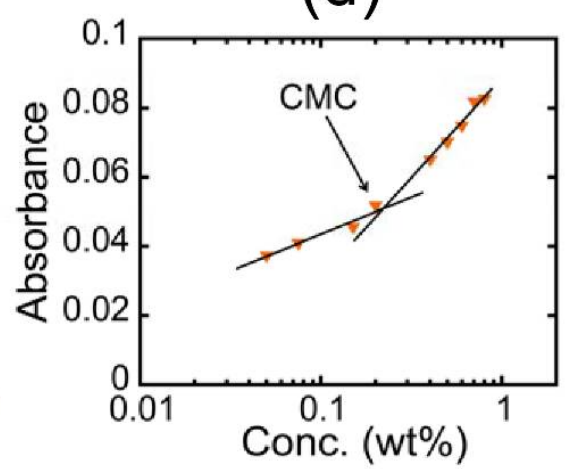

(e)

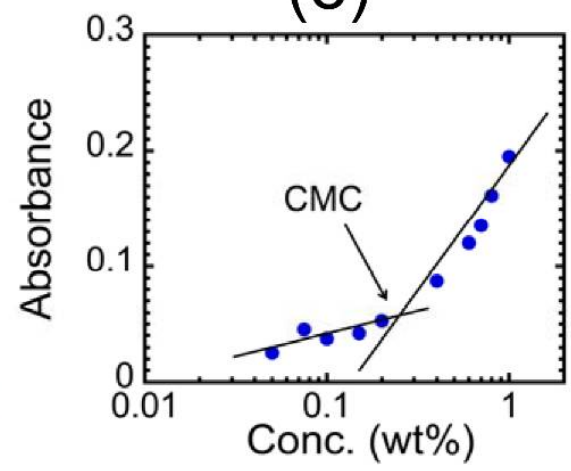

(f)

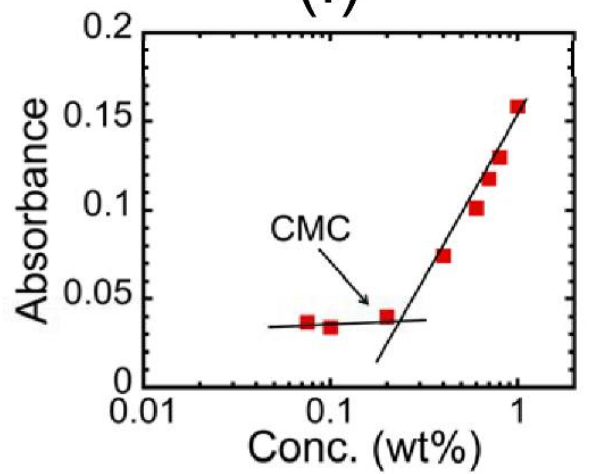

Figure 4. UV-vis spectra of (a) HE-Pep, (b) Pr-Pep, and (c) Me-Pep at various concentrations and the absorbance of (d) HE-Pep (orange triangle), (e) Pr-Pep (blue circle), and (f) Me-Pep (red square) at $340 \mathrm{~nm}$ as a function of concentration (wt \%) at $25^{\circ} \mathrm{C}$.

We next measured the UV-vis spectra of the aqueous solutions at various temperatures and plotted the dependence of transmittance at $450 \mathrm{~nm}$ on temperature (Figure 5). All the aqueous solutions exhibited UCST behaviors, strongly providing evidence that the alternating binary pattern would induce UCST behaviors. Curiously, it was found that the aqueous solutions of HE-Pep exhibited a clearly higher cloud point than that of Et-Pep (Figure 5d), despite HE-Pep comprising hydroxyl 
groups as a hydrophilic functionality. Furthermore, the cloud point of Pr-Pep appeared at a lower temperature than that of Et-Pep (Figure 5e), in spite of the longer hydrophobic side chains of Pr-Pep compared to Et-Pep. The results suggest some special polymer effects of the alternating peptide skeleton that reverses the trend of UCST-based cloud points [21,22]. At this moment, we noticed that the tendency observed in Figure 2c was not dependent only on the difference of secondary structures of the alternating peptides. Aside from the cloud point, the transmittance of Pr-Pep slightly decreased at the higher temperatures compared with that at around $20^{\circ} \mathrm{C}$, implying that the thermal aggregates of hydrophobic side chains would afford an additional cloud point upon heating [23]. The cloud point of Me-Pep appeared at a slightly higher temperature than that of Et-Pep (Figure 5f).

(a)

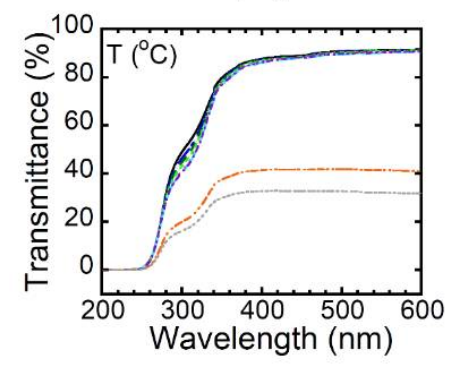

(b)

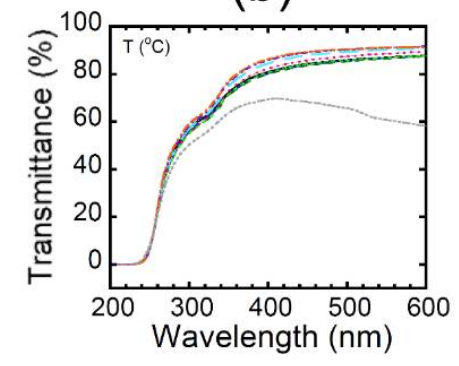

(c)

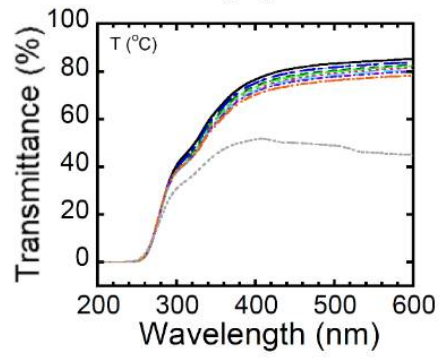

(d)

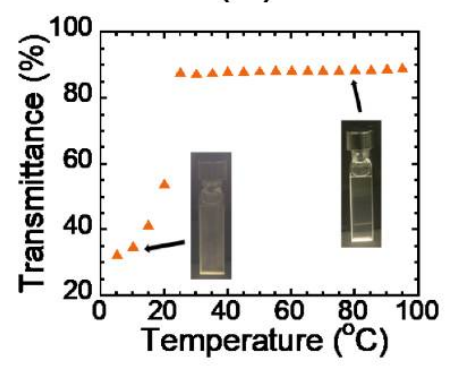

(e)

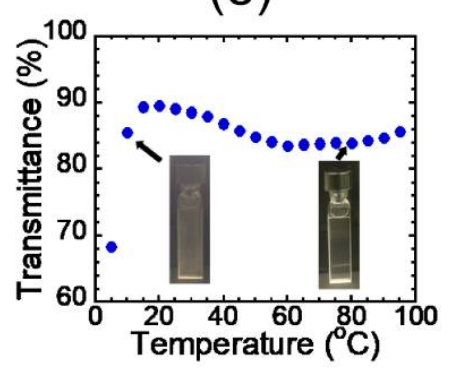

(f)

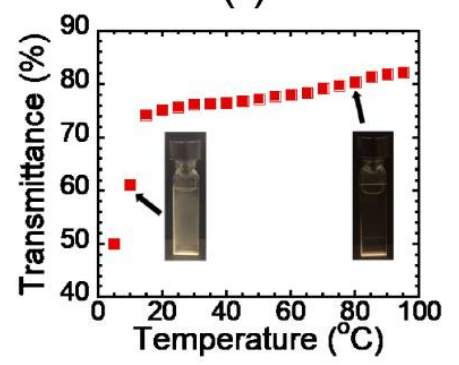

Figure 5. UV-vis spectra of (a) HE-Pep, (b) Pr-Pep, and (c) Me-Pep at various temperatures and the temperature dependence of transmittance of (d) HE-Pep (orange triangle), (e) Pr-Pep (blue circle), and (f) Me-Pep (red square) at $450 \mathrm{~nm}(1.5 \mathrm{wt} \%)$.

For the elucidation of such unusual tendency of cloud points, we next estimated the difference of hydrodynamic radius $\left(R_{\mathrm{h}}\right)$ between HE-Pep and Pr-Pep [24]. With the use of an Einstein-Stokes equation $\left(R_{\mathrm{h}}=k_{\mathrm{B}} \mathrm{T} / 6 \pi \eta D, k_{\mathrm{B}}\right.$ : Boltzmann constant, $\mathrm{T}$ : absolute temperature, $\eta$ : viscosity, $D$ : diffusion coefficient), we performed diffusion-ordered NMR spectroscopic (DOSY) measurements to evaluate the diffusion coefficients of each polymer at $25^{\circ} \mathrm{C}$ in both $\mathrm{D}_{2} \mathrm{O}$ (Figures S2, S7, S12, S17 and S22) and $\mathrm{CF}_{3} \mathrm{COOD}$ (trifluoroacetic acid, TFA-d, Figures S1, S6, S11, S16 and S21). It has been reported that typical polypeptides adopt a random-coil structure in TFA. The $D$ values in $\mathrm{D}_{2} \mathrm{O}$ were estimated by using $0.15 \mathrm{wt} \%$ polymer solutions below the CMCs, considering the estimation of size for single polymer chains. The $D$ values of a chosen chemical shift in the DOSY spectra were extracted by using 
the inversion of Laplace transform driven by the Dynamics center software (Bruker). By introducing the obtained $D$ values in the Einstein-Stokes equation, the $R_{\mathrm{h}}$ values were estimated and are summarized in Table 1 . The $R_{\mathrm{h}}$ value in $\mathrm{D}_{2} \mathrm{O}\left(R_{\text {water }}\right)$ for HE-Pep was found to be of the same order to that in TFA- $d$ $\left(R_{\text {TFA }}\right)$. On the other hand, the $R_{\text {water }}$ of Pr-Pep was clearly lower than the $R_{\text {TFA }}$ of Pr-Pep. The results indicate that Pr-Pep may adopt a globular structure in $\mathrm{D}_{2} \mathrm{O}$, while HE-Pep could form a relatively extended structure such as a random-coil structure even in $\mathrm{D}_{2} \mathrm{O}$.

Table 1. CMC, cloud point, and hydrodynamic radius $\left(R_{\mathrm{h}}\right)$ of HE-Pep and Pr-Pep ${ }^{a}$.

\begin{tabular}{cccccc}
\hline $\begin{array}{c}\text { Alternating } \\
\text { Peptide }\end{array}$ & $\begin{array}{c}\text { CMC } \\
(\mathbf{w t} \%)\end{array}$ & $\begin{array}{c}\text { Cloud Point } \\
(\mathbf{C})\end{array}$ & $\begin{array}{c}\boldsymbol{R}_{\mathbf{h}} \text { in } \mathbf{D}_{\mathbf{2}} \mathbf{O} \\
\left(\boldsymbol{R}_{\text {water }}, \mathbf{n m}\right)\end{array}$ & $\begin{array}{c}\boldsymbol{R}_{\mathbf{h}} \text { in TFA-d } \\
\left(\boldsymbol{R}_{\text {TFA }}, \mathbf{n m}\right)\end{array}$ & $\boldsymbol{R}_{\text {water }} / \boldsymbol{R}_{\text {TFA }}$ \\
\hline HE-Pep & 0.2 & 25 & $0.581 \pm 0.014$ & $0.576 \pm 0.004$ & 1.01 \\
Pr-Pep & 0.2 & 15 & $0.442 \pm 0.011$ & $0.507 \pm 0.005$ & 0.87 \\
\hline
\end{tabular}

${ }^{a}$ Standard deviations are from three samples. TFA: trifluoroacetic acid.

Considering the solvent dependency of the $R_{\mathrm{h}}$ values, the trend of UCST-based cloud points of alternating peptides seems to be correlated to the quasi-stable single polymer structures in water. The structure of HE-Pep presents regularly aligned hydroxyl groups in the same direction and can be regarded as a Janus structure [25]. The hydrophobic alkyl chains may be exposed in an organic solvent, which could be accompanied by the association of hydroxyl group-containing side chains. In contrast, the hydroxyl group-containing side chains could be projected outward in water along with the association of hydrophobic alkyl chains. As a result, the Janus structure of HE-Pep would make the $R_{\mathrm{h}}$ values in an organic solvent and water similar. Since the peptide main chain of Pr-Pep as an organophobe would be efficiently covered by the hydrophobic side chains, Pr-Pep is expected to adopt an extended structure in an organic solvent. However, the hydrophilic main chain of Pr-Pep would be exposed in water along with the aggregation of hydrophobic side chains, which could be accompanied by the trans-cis isomerization of $N, N$-disubstituted amides because of the low rotation energy. The structural isomerization of Pr-Pep should be a plausible reason for the contraction of the polymer in water. In addition to the hydrophilic-lipophilic balance of alternating peptides, the morphology of quasi-stable single polymer chains in water would be related to the opposite trend of UCST-based cloud points. HE-Pep could adopt a relatively extended structure in water compared with the other $\mathrm{N}$-substituted alternating peptides, which might facilitate the formation of second associates upon cooling, leading to the high cloud point of HE-Pep. Detailed studies of the morphology of single polymer chains will be performed as a part of our future work.

\section{Materials and Methods}

Glycyl-L-valine (Tokyo Chemical Industry Co., Ltd., Tokyo, Japan), O-(7-azabenzotriazole-1-yl)$N, N, N^{\prime}, N^{\prime}$-tetramethyluronium hexafluorophosphate (HATU, Tokyo Chemical Industry Co., Ltd.), isobutyraldehyde (Tokyo Chemical Industry Co., Ltd., Tokyo, Japan), ethylammonium chloride (FUJIFILM Wako Pure Chemical Corporation, Osaka, Japan), I-propyl alcohol (Taiyo Chemicals, Co., Ltd., Wakayama, Japan), 2-aminoethanol (FUJIFILM Wako Pure Chemical Corporation, Osaka, Japan), propylammonium chloride (FUJIFILM Wako Pure Chemical Corporation, Osaka, Japan), methylammonium chloride (FUJIFILM Wako Pure Chemical Corporation, Osaka, Japan) were used as obtained. Potassium isocyanoacetate was synthesized according to the literature [26].

The ${ }^{1} \mathrm{H}$ NMR $(400 \mathrm{MHz})$ and ${ }^{13} \mathrm{C}$ NMR $(100 \mathrm{MHz})$ spectra were recorded on a Bruker Avance II 400 spectrometer (Bruker, Fällanden, Switzerland), using $\mathrm{CDCl}_{3}$ as a solvent, and calibrated using residual undeuterated solvent and tetramethylsilane as internal standards. Diffusion-ordered NMR spectroscopic analyses (DOSY) were carried out using the alternating peptides in $\mathrm{CF}_{3} \mathrm{COOD}$ (TFA- $d$ ) or in $\mathrm{D}_{2} \mathrm{O}$ at highly diluted concentrations to estimate the diffusion coefficients. Experiments were run without spinning to avoid convection. The standard Bruker pulse program ledbpgp2s was used, which employs simulated echo and longitudinal eddy delay with bipolar gradients and two spoil 
gradients. The diffusion coefficients of a selected narrow chemical shift in the spectra of the compounds were determined using the Dynamics Center software (ver. 2.4.8; Bruker, Fällanden, Switzerland). The calibration line in TFA- $d$ for $M_{\mathrm{w}}$ prediction was obtained by the diffusion coefficients of angiotensin II (MW: 1064.18, $\log D:-9.38)$, insulin (MW: 5807.57, $\log D ;-9.77)$ and cytochrome C (MW: 12384, $\log D:-9.87)$ as standards [8,27]. Fourier-transform infrared (FTIR) spectra of the samples in solid state were recorded via an attenuated total reflection (ATR) method using a PerkinElmer spectrum 100 spectrometer (PerkinElmer, Shelton, USA). UV-vis spectra were recorded on a JASCO V-550 spectrophotometer (JASCO Co. Ltd., Tokyo, Japan) using a $1.0 \mathrm{~mm}$ path quartz cell with a temperature controller (ETC-505T, JASCO Co. Ltd., Tokyo, Japan).

\subsection{Synthesis of Poly(Gly-alter-L-Val)}

$\mathrm{Et}_{3} \mathrm{~N}(1.91 \mathrm{~mL}, 13.8 \mathrm{mmol})$ and HATU $(4.92 \mathrm{~g}, 12.9 \mathrm{mmol})$ were added to a solution of glycyl-L-valine $(1.5 \mathrm{~g}, 8.61 \mathrm{mmol})$ in DMSO $(8.4 \mathrm{~mL})$ at room temperature. After stirring for $8 \mathrm{~d}, \mathrm{MeOH}(90 \mathrm{~mL}) \mathrm{was}$ added to the mixture. The mixture was sonicated and filtered to collect white solids, which were further washed with $\mathrm{MeOH}$ and $\mathrm{CHCl}_{3}$ and dried in vacuo to give poly(Gly-alter-L-Val) (1.72 g) in quantitative yield: $M_{\mathrm{w}}$ 2,900 Da (estimated by NMR, Figure S1); IR (ATR) $v 3278$ (NH), 2965, 1628 $(\mathrm{C}=\mathrm{O}), 1534,1498,1457,1432,1411,1323,1272,1222,1180,1109,1041,1026,842,706 \mathrm{~cm}^{-1}$ (Figure S3).

\subsection{Synthesis of Et-Pep}

Ethylammonium chloride $(463 \mathrm{mg}, 5.68 \mathrm{mmol})$ was added to $i$-PrOH $(2.9 \mathrm{~mL})$, followed by the addition of isobutylaldehyde $(519 \mu \mathrm{L}, 5.68 \mathrm{mmol})$ and potassium isocyanate $(700 \mathrm{mg}, 5.68 \mathrm{mmol})$. The reaction mixture was dissolved by sonication. The mixture was stirred for $8 \mathrm{~d}$ at room temperature and concentrated in vacuo. The resulting crude mixture was further stirred for $6 \mathrm{~d}$ at room temperature and diluted with THF to precipitate inorganic salts. The mixture was filtered and concentrated in vacuo to give the corresponding alternating peptide (Et-Pep, $1.12 \mathrm{~g}$ ) in quantitative yield: $M_{\mathrm{w}} 1000 \mathrm{Da}$ (estimated by NMR, Figure S6); ${ }^{13} \mathrm{C}$ NMR (100 MHz, $\left.298 \mathrm{~K}, \mathrm{CDCl}_{3}\right) \delta 172-160(\mathrm{C}=\mathrm{O}), 68.0(\mathrm{CH})$, 43.4-43.3 ( $\left.\mathrm{CH}_{2}\right), 34.8-30.4(\mathrm{CH}), 27.4-13.4\left(\mathrm{CH}_{2}, \mathrm{CH}_{3}\right)$ ppm (Figure S5); IR (ATR) v3281 (NH), 2968, 2875, 1647 (C=O), 1533, 1466, 1381, 1264, 1233, 1105, $930 \mathrm{~cm}^{-1}$ (Figure S8).

\subsection{Synthesis of Pr-Pep}

Propylammonium chloride $(543 \mathrm{mg}, 5.68 \mathrm{mmol})$ was added to $i$-PrOH $(2.9 \mathrm{~mL})$, followed by the addition of isobutylaldehyde $(519 \mu \mathrm{L}, 5.68 \mathrm{mmol})$ and potassium isocyanate $(700 \mathrm{mg}, 5.68 \mathrm{mmol})$. The reaction mixture was dissolved by sonication. The mixture was stirred for $8 \mathrm{~d}$ at room temperature and concentrated in vacuo. The resulting crude mixture was further stirred for $6 \mathrm{~d}$ at room temperature and diluted with THF to precipitate inorganic salts. The mixture was filtered and concentrated in vacuo to give the corresponding alternating peptide (Pr-Pep, 1.24g) in quantitative yield: $M_{\mathrm{w}} 800 \mathrm{Da}$ (estimated by NMR, Figure S16); ${ }^{13} \mathrm{C}$ NMR (100 MHz, $\left.298 \mathrm{~K}, \mathrm{CDCl}_{3}\right) \delta 174-160(\mathrm{C}=\mathrm{O}), 68.2-67.3(\mathrm{CH})$, 50.5-41.5 $\left(\mathrm{CH}_{2}\right), 30.7-25.8(\mathrm{CH}), 22.9-11.6\left(\mathrm{CH}_{2}, \mathrm{CH}_{3}\right)$ ppm (Figure S15); IR (ATR) v3281 (NH), 2963, 2876, 1647 (C=O), 1533, 1466, 1382, 1229, 1105, 1028, $958 \mathrm{~cm}^{-1}$ (Figure S18).

\subsection{Synthesis of HE-Pep}

The compound 2-aminoethanol $(0.69 \mathrm{~mL}, 11.5 \mu \mathrm{mol})$ was treated with $1.0 \mathrm{M} \mathrm{HCl}$ aq. (12 mL) at $0{ }^{\circ} \mathrm{C}$, concentrated in vacuo, and dried under reduced pressure at $70{ }^{\circ} \mathrm{C}$ to give 2-aminoethanol hydrochloride. The obtained 2-aminoethanol hydrochloride ( $544 \mathrm{mg}, 5.68 \mathrm{mmol})$ was added to $i$-PrOH $(2.9 \mathrm{~mL})$, followed by the addition of isobutylaldehyde $(519 \mu \mathrm{L}, 5.68 \mathrm{mmol})$ and potassium isocyanate (700 $\mathrm{mg}, 5.68 \mathrm{mmol})$. The reaction mixture was dissolved by sonication. The mixture was stirred for $8 \mathrm{~d}$ at room temperature and concentrated in vacuo. The resulting crude mixture was further stirred for $6 \mathrm{~d}$ at room temperature and diluted with THF to precipitate inorganic salts. The mixture was filtered and concentrated in vacuo to give the corresponding alternating peptide (HE-Pep, 1.25g) in a quantitative yield: $M_{\mathrm{w}}$ 1,100 Da (estimated by NMR, Figure S11); ${ }^{13} \mathrm{C}$ NMR $\left(100 \mathrm{MHz}, 298 \mathrm{~K}, \mathrm{CDCl}_{3}\right) \delta 174-169$ 
(C=O), 68.6-60.1 (CH), 47.7-42.2 ( $\left.\mathrm{CH}_{2}\right), 30.5-29.2(\mathrm{CH}), 25.6-16.6\left(\mathrm{CH}_{2}, \mathrm{CH}_{3}\right)$ ppm (Figure S10); IR (ATR) $v 3287(\mathrm{NH}), 2962,2873,1647(\mathrm{C}=\mathrm{O}), 1539,1466,1387,1188,1039,1029,959 \mathrm{~cm}^{-1}$ (Figure S13).

\subsection{Synthesis of Me-Pep}

Methylammonium chloride ( $384 \mathrm{mg}, 5.68 \mathrm{mmol})$ was added to $-i-\mathrm{PrOH}(2.9 \mathrm{~mL})$, followed by the addition of isobutylaldehyde $(519 \mu \mathrm{L}, 5.68 \mathrm{mmol})$ and potassium isocyanate $(700 \mathrm{mg}, 5.68 \mathrm{mmol})$. The reaction mixture was dissolved by sonication. The mixture was stirred for $8 \mathrm{~d}$ at room temperature and concentrated in vacuo. The resulting crude mixture was further stirred for $6 \mathrm{~d}$ at room temperature and diluted with THF to precipitate inorganic salts. The mixture was filtered and concentrated in vacuo to give the corresponding alternating peptide (Me-Pep, $1.05 \mathrm{~g}$ ) in a quantitative yield: $M_{\mathrm{w}} 1000 \mathrm{Da}$ (estimated by NMR, Figure S21); ${ }^{13} \mathrm{C}$ NMR $\left(100 \mathrm{MHz}, 298 \mathrm{~K}, \mathrm{CDCl}_{3}\right) \delta 174-162(\mathrm{C}=\mathrm{O}), 75.2-68.1(\mathrm{CH})$, 45.1-41.8 $\left(\mathrm{CH}_{2}\right), 33.5-31.7(\mathrm{CH}), 22.6-16.8\left(\mathrm{CH}_{3}\right)$ ppm (Figure S20); IR (ATR) v3285 (NH), 2963, 1645 $(\mathrm{C}=\mathrm{O}), 1531,1468,1410,1386,1230,1164,1104,1027 \mathrm{~cm}^{-1}$ (Figure S23).

\subsection{Determination of Critical Micelle Concentration (CMC)}

Stock solutions of the polymer samples were prepared by dissolution in $\mathrm{H}_{2} \mathrm{O}$. The aqueous solutions at various concentrations were prepared using the stock solution by proper dilution. The UV-vis spectra of the sample solutions were recorded on a JASCO V-550 spectrophotometer (JASCO Co. Ltd., Tokyo, Japan) using a $1.0 \mathrm{~mm}$ path quartz cell at $25^{\circ} \mathrm{C}$. The obtained absorbance values at $340-350 \mathrm{~nm}$ were standardized by the concentration and were plotted as a function of the concentration. From the intersection point in the plots, we determined the CMC values of the polymers in water.

\subsection{Determination of Cloud Point}

The cloud points of the polymers were determined by the UV-vis spectra of $1.5 \mathrm{wt} \%$ polymer aqueous solutions at various temperatures $\left(5-95^{\circ} \mathrm{C}\right)$. The obtained transmittance values were plotted as the function of temperature. From the plots, we determined the cloud points of the polymers as the onset temperature to become translucent upon cooling.

\subsection{Estimation of the Hydrodynamic Radius}

We measured DOSY spectra using solutions at various concentrations in aqueous $\left(\mathrm{D}_{2} \mathrm{O}\right)$ and organic solvents (TFA- $d$ ) to estimate the diffusion coefficients $(D)$. For example, the DOSY spectrum was obtained using HE-Pep $(0.9 \mathrm{mg})$ in $\mathrm{D}_{2} \mathrm{O}(0.6 \mathrm{~mL})$ to estimate the $D$ value for single polymer chains at $298 \mathrm{~K}$ (Figure S12). The experiment was run without spinning to avoid convection. The standard Bruker pulse program ledbpgp2s was used, which employs simulated echo and longitudinal eddy delay with bipolar gradients and two spoil gradients. The diffusion coefficients of a selected narrow chemical shift in the spectra of the compounds were extracted by using the inversion of Laplace transform driven by the Dynamics Center software (ver. 2.4.8; Bruker, Fällanden, Switzerland). By introducing the obtained $D$ values in the Einstein-Stokes equation $\left(R_{\mathrm{h}}=k_{\mathrm{B}} \mathrm{T} / 6 \pi \eta D, k_{\mathrm{B}}\right.$ : Boltzmann constant, T: absolute temperature, $\eta$ : viscosity, $D$ : diffusion coefficient), we estimated the $R_{\mathrm{h}}$ values of the polymers to be $0.581 \pm 0.014 \mathrm{~nm}$ (Table 1). For the other polymers, we estimated the $R_{\mathrm{h}}$ values in a similar manner (Table 1 and Table S1).

\section{Conclusions}

In conclusion, we designed and investigated the micellization behaviors of alternating peptides in water. The effects of substituents on the amide nitrogen atoms were systematically investigated using the reliable polymer structure consisting of exactly alternating peptides. The alternating peptides were successfully prepared via three-component polymerization exploiting Ugi's four-component polymerization as the elemental polymerization reaction. The micellization behaviors of alternating peptides were evaluated by analyzing their UV-vis spectra at various concentrations and temperatures 
and DOSY measurements in $\mathrm{D}_{2} \mathrm{O}$ and TFA- $d$. All the aqueous solutions of the polymers exhibited UCST behaviors. It turned out that the cloud points of alternating peptides shifted to higher temperatures as the side chains became more hydrophilic, which is clearly opposite to the trend of typical surfactants. The comparison of $R_{\mathrm{h}}$ values in $\mathrm{D}_{2} \mathrm{O}$ and TFA- $d$ indicated that this opposite trend of cloud points is closely related to the regular alignment of $N$-substituents of alternating peptides. The present study provides new insights not only for the rational control of amphiphilicity of peptides but also for the control of their micellar properties. Due to the biodegradable nature [28] and controlled micellar properties, these peptides might have applications as drug carriers in the field of pharmaceutical engineering.

Supplementary Materials: Supplementary materials can be found at http://www.mdpi.com/1422-0067/20/18/ 4604/s1.

Author Contributions: A.B.I. and M.N. performed the experiments and analyzed the data in the manuscript. Y.K. conceived the hypothesis, designed the experiments, and wrote the manuscript. All authors read and approved the final manuscript.

Funding: This work was financially supported by the Hitachi Metals Materials Science Foundation, the Iketani Science and Technology Foundation, JSPS KAKENHI (Grant Number JP17H03070), and the Grant-in-Aid for JSPS Fellows relating to JSPS Postdoctoral Fellowships for Foreign Researchers (No. P19038 for A.B.I.) from JSPS.

Conflicts of Interest: The authors declare no conflict of interest.

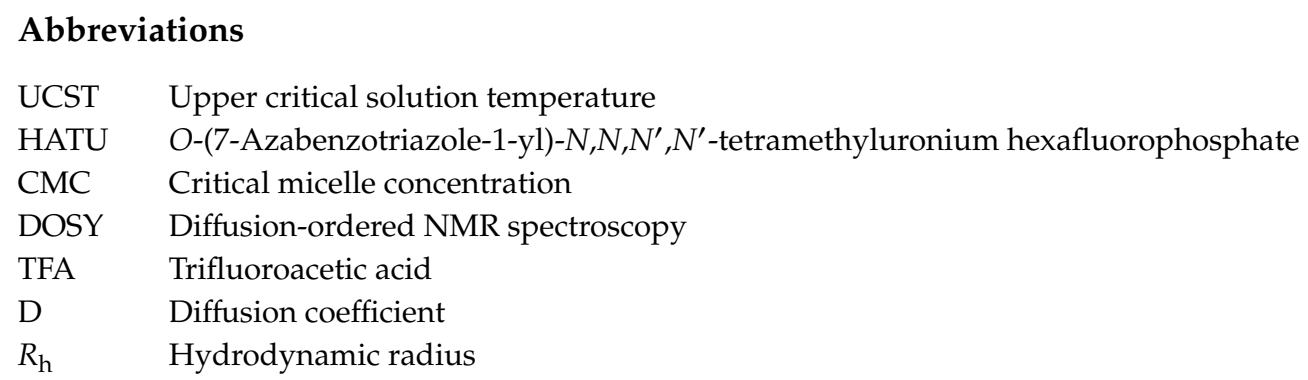

\section{References}

1. Cavalli, S.; Albericio, F.; Kros, A. Amphiphilic peptides and their cross-disciplinary role as building blocks for nanoscience. Chem. Soc. Rev. 2010, 39, 241-263. [CrossRef] [PubMed]

2. Hamley, I.W. Self-assembly of amphiphilic peptides. Soft Matter 2011, 7, 4122-4138. [CrossRef]

3. Dexter, A.F.; Middelberg, A.P.J. Peptides as functional surfactants. Ind. Eng. Chem. Res 2008, 47, 6391-6398. [CrossRef]

4. Dehsorkhi, A.; Castelletto, V.; Hamley, I.W. Self-assembling amphiphilic peptides. J. Pept. Sci. 2014, 20, 453-467. [CrossRef] [PubMed]

5. Qin, F.; Chen, Y.; Tang, C.; Zhao, X. Amphiphilic peptides as novel nanomaterials: Design, self-assembly and application. Int. J. Nanomed. 2018, 13, 5003-5022.

6. Ihsan, A.B.; Koyama, Y. Impact of polypeptide sequence on thermal properties for diblock, random, and alternating copolymers containing a stoichiometric mixture of glycine and valine. Polymer 2019, 161, 197-204. [CrossRef]

7. Chanachichalermwong, W.; Charoensaeng, A.; Suriyapraphadilok, U. Krafft point prediction of anionic surfactants using group contribution method: First-order and higher-order groups. J. Surfact. Deterg. 2019. [CrossRef]

8. Koyama, Y.; Gudeangadi, P.G. One-pot synthesis of alternating peptides exploiting a new polymerization technique based on Ugi's 4CC reaction. Chem. Commun. 2017, 53, 3846-3849. [CrossRef]

9. Cai, L.; Gochin, M.; Liu, K. A facile surfactant critical micelle concentration determination. Chem. Commun. 2011, 47, 5527-5529. [CrossRef]

10. Nesměrák, K.; Němcová, I. Determination of critical micelle concentration by electrochemical means. Anal. Lett. 2006, 39, 1023-1040. [CrossRef] 
11. Mukerjee, P. Critical micelle concentrations of aqueous surfactant systems. In National Standard Reference Data System, National Bureau of Standards; U.S. Department of Commerce, Ed.; U.S. Government Printing Office: Washington, DC, USA, 1971; pp. 1-222.

12. Li, N.; Luo, H.; Liu, S. A new method for the determination of the critical micelle concentration of Triton X-100 in the absence and presence of $\beta$-cyclodextrn by resonance Rayleigh scattering technology. Spectrochim. Acta Part A Mol. Biomol. Spectrosc. 2004, 60, 1811-1815. [CrossRef] [PubMed]

13. Chan, C.Y.; Wang, S.J.; Liu, I.J.; Chiu, Y.C. A simple method for determining the critical micellar concentration of a surfactant. J. Chin. Chem. Soc. 1987, 34, 243-246. [CrossRef]

14. Mandavi, R.; Sar, S.K.; Ranthore, N. Critical micelle concentration of surfactant, mixed-surfactant and polymer by different method at room temperature and its importance. Orient. J. Chem. 2008, 24, 559-564.

15. Ghosh, S.; Krishnan, A.; Das, P.K.; Ramakrishnan, S. Determination of critical micelle concentration by hyper-Rayleigh scattering. J. Am. Chem. Soc. 2003, 125, 1602-1606. [CrossRef] [PubMed]

16. Oh, H.J.; Joo, M.K.; Sohn, Y.S.; Jeong, B. Secondary structure effect of polypeptide on reverse thermal gelation and degradation of L/DL-poly(alanine)-poloxamer-L/DL-poly(alanine) copolymers. Macromolecules 2008, 41, 8204-8209. [CrossRef]

17. Cheng, Y.; He, C.; Xiao, C.; Ding, J.; Zhuang, X.; Huang, Y.; Chen, X. Decisive role of hydrophobic side groups of polypeptides in thermosensitive gelation. Biomacromolecules 2012, 13, 2053-2059. [CrossRef] [PubMed]

18. Stewart, W.E.; Siddall, T.H., III. Nuclear magnetic resonance studies of amides. Chem. Rev. 1970, 70, 517-551. [CrossRef]

19. Aya, T.; Isao, A.; Hiroyuki, K. Aromatic architecture based on cis conformational preference of $N$-methylated amides. Yuki Gosei Kagaku Kyokaishi 2000, 58, 556-567.

20. Rapaport, H.; Kjaer, K.; Jensen, T.R.; Leiserowitz, L.; Tirrell, D.A. Two-dimensional order in $\beta$-sheet peptide monolayers. J. Am. Chem. Soc. 2000, 122, 12523-12529. [CrossRef]

21. Kaewsaiha, P.; Matsumoto, K.; Matsuoka, H. Non-surface activity and micellization of ionic amphiphilic diblock copolymers in water. Hydrophobic chain length dependence and salt effect on surface activity and the critical micelle concentration. Langmuir 2005, 21, 9938-9945. [CrossRef]

22. Matsuoka, H.; Chen, H.; Matsumoto, K. Molecular weight dependence of non-surface activity for ionic amphiphilic diblock copolymers. Soft Matter 2012, 8, 9140-9146. [CrossRef]

23. Koyama, Y.; Ihsan, A.B.; Gudeangadi, P.G. Synthetic approach of thermally tunable nature-mimetic polypeptides from $N$-protected alternating peptoids. Macromol. Chem. Phys. 2018, 219, 1800303. [CrossRef]

24. Ihsan, A.B.; Koyama, Y.; Taira, T.; Imura, T. Thermo-responsive structure and surface activity of kinetically stabilized micelle composed of fluorinated alternating peptides in organic solvent. ChemistrySelect 2018, 3, 4173-4178. [CrossRef]

25. Walther, A.; Müller, A.H.E. Janus particles: Synthesis, self-assembly, physical properties, and applications. Chem. Rev. 2013, 113, 5194-5261. [CrossRef] [PubMed]

26. Bonne, D.; Dekhane, M.; Zhu, J. Ammonium chloride promoted Ugi four-component, five-center reaction of $\alpha$-substituted $\alpha$-isocyano acetic acid: A strong solvent effect. Org. Lett. 2004, 6, 4771-4774. [CrossRef] [PubMed]

27. Li, W.; Chung, H.; Daeffler, C.; Johnson, J.A.; Grubbs, R.H. Application of ${ }^{1} \mathrm{H}$ DOSY for facile measurements of polymer molecular weights. Macromolecules 2012, 45, 9595-9603. [CrossRef] [PubMed]

28. Tsuchiya, K.; Ifuku, N.; Koyama, Y.; Numata, K. Development of regenerated silk films coated with fluorinated polypeptides to achieve high water repellency and biodegradability in seawater. Polym. Degrad. Stab. 2019, 160, 96-101. [CrossRef]

(C) 2019 by the authors. Licensee MDPI, Basel, Switzerland. This article is an open access article distributed under the terms and conditions of the Creative Commons Attribution (CC BY) license (http://creativecommons.org/licenses/by/4.0/). 